\title{
A RELAÇÃO DO FUNK COM A CULTURA ESCOLAR: ENTRE DILEMAS E TENSÕES ${ }^{1}$
}

\author{
Fernanda Xavier Machado \\ Secretaria de Educação do Estado do Espírito Santo, Serra, Espírito Santo, Brasil. \\ Felipe Quintão de Almeida \\ Universidade Federal do Espírito Santo, Vitória, Espírito Santo, Brasil. \\ Ivan Marcelo Gomes \\ Universidade Federal do Espírito Santo, Vitória, Espírito Santo, Brasil.
}

\begin{abstract}
Resumo
O objetivo deste estudo foi entender os elementos que dão visibilidade e invisibilidade ao funk dentro de um ambiente escolar. Para tanto, esta pesquisa desenvolveu-se em uma escola de um bairro periférico do município de Serra (Espírito Santo). O método adotado teve um caráter etnográfico, sendo os dados coletados através de observações diretas e indiretas, registros em diário de campo e entrevistas semiestruturadas. Tais procedimentos foram aplicados com os sujeitos centrais da investigação, representados nas figuras dos alunos e do corpo docente. Os resultados mostraram a existência de conflitos e entraves dentro da escola investigada, no que se refere à sua relação com o funk.
\end{abstract}

Palavras-chave: Juventude. Funk. Escola.

\section{THE RELATIONSHIP OF FUNK WITH SCHOOL CULTURE: BETWEEN DILEMMAS AND TENSIONS}

\begin{abstract}
This study aimed to understand the elements that give visibility and invisibility to funk within a school environment. In order to achieve this goal, a field research was conducted in a school located in the outskirts of Serra (Espírito Santo, Brazil). Following an ethnographic approach, data were collected through direct and indirect observations, records in field journal and semistructured interviews. These procedures were used with the central research subjects, namely the students and teachers. The results showed the existence of conflicts and obstacles within the investigated school regarding its relation with funk.
\end{abstract}

Key words: Youth. Funk. School.

\footnotetext{
${ }^{1}$ A presente investigação recebeu auxílio financeiro (modalidade bolsa de mestrado) da Coordenação de Aperfeiçoamento de Pessoal de Nível Superior (CAPES). 


\section{LA RELACIÓN DEL FUNK CON LA CULTURA ESCOLAR: ENTRE DILEMAS Y TENSIONES}

\section{Resumen}

El objetivo de este trabajo fue entender los elementos que dan visibilidad e invisibilidad al funk dentro del ambiente escolar. Esta investigación se desarrolló en una escuela de un barrio periférico del município de Serra (Espírito-Santo). El método adoptado tuvo un carácter etnográfico, con los datos recogidos por medio de observaciones directas e indirectas, registros en diario de campo y entrevistas semiestructuradas. Tales procedimientos fueron aplicados con los sujetos centrales de la investigación, representados por los alumnos y cuerpo docente. Los resultados demuestran la existencia de conflictos y tensiones en el interior de la escuela estudiada, en lo que se refiere a su relación con el funk.

Palabras clave: Juventud. Funk. Escuela.

\section{Introdução}

Grito da favela, voz do morro cantando a liberdade, som da massa. Esse é o modo como Facina (2009) refere-se ao funk, que hoje se apresenta como a face das periferias de todo o país. Considerado como um estilo musical tipicamente brasileiro, o funk é descendente direto da música produzida nos guetos norte-americanos em meados do século XX. De acordo com Vianna (1988), nos anos finais da década de 1980, o som que nasce nos subúrbios estadunidenses ganha notoriedade inicialmente no Canecão, tradicional casa de shows localizada em meio aos bairros luxuosos da zona sul da capital do estado do Rio de Janeiro. Tal como aponta Medeiros (2006), algum tempo depois, o som é expulso da parte nobre da cidade, invadindo as quadras esportivas e os clubes no subúrbio, tornando-se, já naquela época, o principal meio de lazer das comunidades periféricas cariocas. De lá para cá, foi justamente nesses espaços que a música negra norte-americana adquiriu características nacionais. Assim como Essinger (2005) apresenta, inicialmente o funk ganhou o tom brincalhão dos "melôs", letras tipicamente brasileiras que contavam o cotidiano dos moradores das periferias cariocas, e, anos mais tarde, a batida eletrônica do som afro-americano transforma-se e recebe o acréscimo do chamado "tamborzão".

Pouco mais de 30 anos depois da sua entrada e consolidação enquanto ritmo brasileiro, o funk torna-se um dos maiores fenômenos de massa do país, estando presente "[...] em festas de crianças, em comemorações empresariais, passando por casamentos e formaturas, configurando-se como o ponto alto da festa" (ROSÁRIO, 2015, p. 45). Embora esse ritmo apresente aspectos ligados ao entretenimento, à diversão e à alegria, Laignier (2012) caracteriza o funk, também, como um elemento cultural multifacetado que carrega na sua história diversas contradições intrínsecas. Esse autor destaca ainda que:

O funk carioca apresenta, inclusive em suas próprias letras, duas tendências aparentemente opostas, sintetizadas aqui como dois lados: um positivo, romântico, leve e até mesmo pragmático, de luta por motivos trabalhistas e questões sociais; e outro negativo, de extrema pornografia [...] fazendo menções às facções componentes dos poderes paralelos e relatando/estimulando relações individualistas entre as pessoas do ponto de vista afetivo, com ênfase no lado sexual (LAIGNIER, 2012, p. 210211).

Embora carregue inúmeras ambiguidades e apresente uma proximidade com questões polêmicas e ilícitas, o ritmo, mesmo assim, possui um forte vínculo cultural com as periferias, algo notável em suas letras, e, também, “[...] acaba influenciando na formação identitária dos 
sujeitos que se apropriam desse elemento, sendo notado por meio de seu linguajar, vestimenta, adornos e posturas" (RANGEL, 2013, p. 114).

Diante dessas considerações, é possível observar que o funk se faz igualmente presente em diversas instâncias da sociedade capixaba e, mais especificamente, na vida de muitos jovens que vivem nas periferias da região metropolitana do Estado do Espírito Santo. A vinculação entre o funk e os jovens dos subúrbios da Grande Vitória-ES foi algo que inicialmente chamou atenção de um dos autores deste artigo, principalmente depois que ele teve suas aulas de Educação Física invadidas pela forte ligação de seus alunos com o ritmo. Embora reconhecendo que aquela relação latente mereceria um trabalho sistematizado, na época, esse autor desconhecia elementos pedagógicos vinculados ao funk na Educação Física. A dificuldade em dialogar especificamente com esse elemento cultural esbarra em considerações como a de Souza (2003), ao apontar que ser aluno não é uma condição inerente à vida das crianças e adolescentes, mas algo que anda junto com as relações construídas fora dos muros das instituições de ensino. Atrelado a essa perspectiva, P. Freire (1997) salienta que o ato de ensinar pode ir além de conteúdos ou de métodos rigorosamente estabelecidos, e o educador pode utilizar a realidade presente na vida dos seus educandos.

Pensando na educação como um ato crítico que auxilie os alunos a refletirem sobre as práticas com que se identificam, surge uma inquietação que deu origem à elaboração de uma dissertação que teve como foco entender os olhares que cercavam o funk dentro do ambiente escolar, principalmente na Educação Física. Desse modo, a primeira fase da pesquisa foi dedicada a dialogar com professores de Educação Física que realizavam trabalhos com o funk em suas aulas, seguindo a lógica de pensar o ritmo, a partir da assimilação e reelaboração dos conhecimentos, constituindo assim, um instrumento de ação para a prática social concreta (BUOGO; LARA, 2009). Entretanto, na busca por práticas que adotassem esse perfil, foi notada a falta de trato pedagógico desse ritmo com a disciplina. Tal comprovação levou-nos a refletir que, talvez, essa carência não fosse uma falha exclusiva do campo em si, mas que poderia ser fruto de barreiras construídas dentro das escolas, que não viabilizavam o desenvolvimento de um trabalho pedagógico vinculado ao ritmo. Assim, para o desenvolvimento dessa questão, este estudo teve como objetivo compreender os elementos que dão visibilidade e invisibilidade ao funk, como elemento cultural, dentro de um determinado ambiente escolar. A partir desse ponto principal, os caminhos que seguem este artigo apresentam a escolha do local de investigação, a descrição dos sujeitos centrais da pesquisa e os procedimentos metodológicos adotados. Para apresentar o conteúdo encontrado no campo, estruturamos um tópico específico, oportunidade para tratar da relação do funk dentro do ambiente investigado. Finalizamos o presente texto com as conclusões a que essa pesquisa nos permitiu chegar até o momento.

\section{"Dominando o território"}

Para compreender as visões estabelecidas em torno do funk dentro do ambiente escolar, decidimos que a pesquisa seria desenvolvida em uma instituição na qual o estilo musical estivesse fortemente presente.

No início do ano de 2014, tivemos a indicação de um colega professor que sinalizou a presença do funk em todas as salas de aula de uma escola na qual trabalhava. Após a constatação desse fato, decidimos nos inserir naquela realidade. Assim, para entender o contexto que envolvia o funk dentro daquela instituição, o estudo assumiu um caráter qualitativo. A etnografia foi o delineamento metodológico utilizado para compreender a trama cotidiana dessa que é uma escola pública estadual de ensino fundamental e médio, localizada em um bairro periférico do município de Serra/ES. Para captar os olhares expostos a respeito do funk em tal escola, empregamos, como instrumento de coleta de dados, registros em diário de campo e 
entrevistas semiestruturadas. Os protagonistas deste estudo foram os alunos, representados por 17 sujeitos, com uma faixa etária entre 12 a 17 anos, escolhidos aleatoriamente entre diferentes turmas, da $5^{\mathrm{a}}$ a $8^{\mathrm{a}}$ séries. Além do grupo citado acima, membros do corpo docente, representado por sete professores, igualmente se configuraram como sujeitos centrais do estudo. Vale destacar também que a escolha dos participantes da pesquisa deu-se pela disponibilidade dos mesmos, não sendo atribuída, além dessa, nenhuma outra forma de seleção.

Durante o período de inserção no campo, que aconteceu entre 21 de maio de 2014 e 19 de dezembro de 2014, foi acompanhada exclusivamente a rotina do turno matutino, através da frequência de aproximadamente quatro vezes por semana. Nesse período, foram observados diversos momentos, como as entradas e saídas tanto de alunos quanto de professores, os intervalos, aulas de Educação Física e o retorno às salas também de ambos, além dos horários de planejamento dos docentes. Para manter a ética, os nomes da escola, do bairro onde está localizada a instituição e de todos os indivíduos citados ao longo do estudo foram ocultados com o intuito de preservar a identidade e a integridade dos participantes. Todos os procedimentos metodológicos que fizeram parte desta pesquisa foram aprovados pelos responsáveis da instituição, pelos docentes, pelos estudantes, por seus responsáveis e também passaram pelo Comitê de Ética em Pesquisa, sendo protocolado com o número 020151/2014.

Como a relação do funk na escola se configura como uma problemática diretamente vinculada a questões de natureza empírica, a pesquisa seguiu o caráter de uma pesquisa qualitativa, que "Trabalha com o universo dos significados, dos motivos, das aspirações, das crenças dos valores e das atitudes" (MINAYO, 2012, p. 21). Dentro dessa lógica, os caminhos metodológicos adotados neste trabalho assumiram as características de experiências relacionadas ao campo de estudo da etnografia; somente com a imersão na realidade proporcionada pela aproximação com este método é possível entender as regras, os costumes e as convenções que regem o objeto estudado. Os dados encontrados foram tratados por meio do confronto com a literatura e também através da análise de conteúdo, que, tal como aponta Bardin (1977), possibilita qualificar as vivências dos sujeitos, bem como suas percepções sobre determinado objeto e seus fenômenos.

É importante salientar, também, que os elementos integrados à cultura corporal de movimento foram os alicerces para a sustentação teórico-metodológica deste estudo, pois essa proposta tem como foco promover dentro das aulas de Educação Física uma reflexão pedagógica referente às produções culturais e históricas da humanidade, uma vez que a sua ausência impede que o homem e sua realidade sejam entendidos dentro de uma visão de totalidade (CASTELLANI FILHO et al., 2009). Assim, com o auxílio de todo o aparato metodológico descrito acima, o próximo eixo deste artigo apresenta os desdobramentos tomados pelo estudo através do diálogo com os resultados encontrados ao longo da pesquisa.

\section{Os compassos e os descompassos provocados pelo funk dentro da escola}

Os resultados obtidos durante a pesquisa de campo mostram que o funk aparece como o elemento cultural preferido de oito dos quinze alunos entrevistados. Esta afirmação pode ser constatada na maioria das entrevistas, nas quais são comuns afirmações como:

O funk está presente na minha vida na escola, fora da escola e dentro de casa. Eu comecei a gostar do funk aqui dentro da escola porque ouvia todo mundo curtindo o funk (Aluno 15).

É, eu gosto muito de dançar, danço muito, mas vou a muitas festas que tocam funk, que são específicas para funk. É uma oportunidade da gente fazer novos amigos, conhecer novas pessoas. Eu costumo não sair muito, mas quando eu saio é para ir a festas que têm funk (Aluna 4). 
O contexto apresentando por essas narrativas indica a presença do funk dentro de uma esfera ampla, uma vez que o ritmo encontra-se presente em diferentes meios sociais da vida dos estudantes. Nesse sentido, é possível associar a fala dos alunos a Vale e Salles (2010), que apontam a música como parte vital da cultura periférica, por ser um aspecto importante dentro dos meios de sociabilidade dos jovens, responsáveis por atribuir tonalidades às formas de interação entre seus pares e com a sociedade.

Além das diversas razões apresentadas pela maioria dos alunos para justificarem o que os aproxima do funk, os dados apontam ainda a intensa presença do estilo no bairro onde se localiza a escola, o mesmo habitado por todos os alunos entrevistados. Essa afirmação foi constatada inicialmente através de uma conversa, realizada no dia 21 julho 2014, na qual três alunas, durante uma das aulas de Educação Física, relataram a existência de festas funk realizadas mensalmente na praça do bairro. Em uma das entrevistas, um dos alunos igualmente faz menção aos eventos, classificando-os como um momento de beber, dançar funk e encontrar com os amigos. Ambas as narrativas indicam a presença do ritmo dentro do bairro, atrelado principalmente a um sentido de lazer e vinculado a entretenimento, apresentando-se, assim, como "A celebração da amizade, de certos laços de vizinhança, mas isso não quer dizer que um dançarino não possa ter outros amigos, em outros lugares, com quem vá a outras festas" (VIANNA, 1988, p. 110).

A ligação dos alunos que integram a comunidade e que se identificam com o ritmo fez-se perceptível durante a pesquisa de campo, principalmente durante as aulas de Educação Física e nos recreios. Esses momentos de interação entre os estudantes mostram que a instituição é palco para os relatos dos principais acontecimentos que marcam o bairro, principalmente nos finais de semana, e que geralmente têm o ritmo funk como ponto central:

Você vê geral falando. Se for festa (funk) aqui no bairro que muita gente da escola vai, tem muito comentário (Aluna 4).

Eles (os alunos) falam assim: Nossa foi massa! Dancei muito, peguei umas quatro ontem (Aluna 6).

Sempre tem alguns que comentam o que aconteceu lá (festas funk). "Você foi na social que teve, foi responsa né!?" (Aluno 10).

A afinidade dos discentes com esse ritmo é igualmente citada na entrevista feita com o professor George, dia 20 de novembro de 2014, que enxerga esse estilo musical como "um elemento de lazer deles [dos alunos], porque, geralmente, tem um MC que eles conhecem, outro que dança, enfim, isso está muito enraizado na vida deles". De acordo com Vale e Salles (2010), a música aparece como elemento importante no processo de sociabilidade dos jovens, na medida em que é identificada como produtora de maneiras de conceber o mundo e de conferir tonalidades às formas de interação entre pares e com a sociedade.

Como parte dos alunos entrevistados destaca, embora o funk seja um elemento cultural presente na instituição, ainda falta diálogo formal em torno dos temas que cercam essa manifestação:

Eles [os professores] não falam, mas acho que eles não gostam muito (Aluna 1). Assim, tem um professor que costuma brincar mais com a gente. Ele nunca falou "Ah, eu gosto de funk", mas é o que dá a entender, porque ele canta algumas letras de funk para poder brincar com a gente (Aluna 3).

Os relatos dos alunos aproximam-se da proposta de Silva (2004), ao apontar que os elementos culturais transportados pelos discentes para dentro do ambiente escolar circulam no meio estudantil, mas não de modo oficial, constituindo-se como um currículo oculto, fazendo parte da escola da vida, mas não da vida oficial da escola. Apesar do distanciamento entre os 
saberes educacionais e o funk, parte dos alunos entrevistados expressou de forma positiva o interesse pela realização de um trabalho mais sistematizado a respeito do estilo musical:

A gente queria que a escola olhasse para o funk de forma diferente, porque eles pensam que todo funkeiro é bandido, que todo funkeiro não presta (Aluna 1).

Tinha que envolver mais o funk nas nossas aulas. Acho que seria legal, bacana, conhecer mais sobre o funk. Eu acho bacana, mas o que falta mesmo aqui é eles valorizarem a cultura que a gente tem, que é muito desvalorizada (Aluno 10).

Sendo o funk um elemento que se insere entre as relações sociais construídas dentro do processo educacional, é importante dizer que enxergamos esse ponto como um integrante da cultura escolar da instituição investigada. É importante destacar que entendemos o conceito de cultura escolar como um conjunto de códigos próprios pertencentes a uma escola, transportados e reelaborados pelos seus principais atores, que se constituem de grupos como:

As famílias, professores, gestores e alunos, os discursos e as linguagens (modos de conversação e comunicação), a organização escolar e o sistema educativo e as práticas (pautas de comportamento que chegam a se consolidar durante um tempo) [...] a escola é uma instituição da sociedade, que possui suas próprias formas de ação e de razão, construídas no decorrer da sua história, tomando por base os confrontos e conflitos oriundos do choque entre as determinações externas a ela e as suas tradições, as quais se refletem na sua organização e gestão, nas suas práticas mais elementares e cotidianas, nas salas de aula e nos pátios e corredores, em todo e qualquer tempo, segmentado, fracionado ou não (SILVA, 2006, p. 202-206).

A proximidade dos alunos com o funk indica uma intencionalidade deles para a realização de um trabalho pedagógico relacionado com o ritmo, como mostram as narrativas:

Pedir para os meninos rimar para as meninas cantarem, colocasse para produzir música, nossa, seria muito legal. Ia ser massa um trabalho com funk aqui, porque a maioria gosta de funk aqui na escola. Seria massa (Aluna 1).

Tinha que trabalhar assim, fazer uma festa, ter uma aula de dança, ou colocar um menino para cantar ou dançar para vê como o funk acontece nas festas, mas não, nada de putaria. Nossa, ia ser massa demais, imagina, você chegar no colégio e ter uma aula de dança (Aluno 14).

Tanto o interesse dos alunos por uma maior abertura para o funk dentro do processo educacional, quanto a possibilidade e a necessidade da realização de um trabalho em torno desse ritmo dentro da instituição aparecem entre as falas de parte dos docentes entrevistados:

Possível sim, mas sofreria a resistência de alguns professores, mas possível. Seria difícil às vezes pelo mesmo motivo do que o meu, por não conhecer. Acho que o interesse sairia dos alunos em estudar esse ritmo. O difícil seria para os professores. (professora Clarissa).

Eu cheguei há pouco tempo e não vejo a equipe dando muita abertura para o funk na escola [...] o funk aqui é muito latente, faz parte do cotidiano deles, não tem como ignorar. É necessário que se parta dessa realidade para levá-los a uma crítica e reflexão sobre isso. Sim, é claro, dá para levantar muitas questões a partir do funk. Reafirmo que pode ser trabalhado de várias maneiras dentro de várias disciplinas dentro da escola (professor Helder).

Embora os relatos acima denunciem a carência e as barreiras existentes na construção de um trato pedagógico que envolva o funk, os dados também enfatizam a importância de um diálogo maior entre os professores. Essa troca é necessária, visto que algumas ações esporádicas são feitas por alguns docentes, que realizam pontes entre suas disciplinas e o ritmo, quando o mesmo emerge durante suas aulas, como aparece no trecho de entrevista abaixo: 
Quando um aluno está na sala cantando uma determinada música eu aproveito o momento para levar eles a refletir sobre aquele funk e questiono se eles já pararam para pensar no que eles estão cantando (professor Helder).

A maior conectividade entre as práticas docentes vai ao encontro de Garbin e Severo (2013), o qual ressalta que a atual condição juvenil desafia-nos a pensar em novas pedagogias como condição necessária para operar nesses novos tempos e espaços, nos quais expressividades juvenis são constantemente (re)inventadas. É importante destacar ainda que a falta de conhecimento, por parte dos professores, em torno dos elementos históricos e sociais que envolvem o ritmo não pode se apresentar como um impedimento para a construção de um trabalho pedagógico que enfoque o funk, já que as ações desenvolvidas por Pinelli e Lara (2007) exemplificam a importância da pesquisa, principalmente por parte dos professores, com o objetivo de superar a falta de conhecimento a respeito desse estilo musical.

As informações produzidas indicam também a importância de se desconstruírem determinados posicionamentos a respeitos do funk dentro do cotidiano escolar em questão, uma vez que o estilo musical é alvo de situações preconceituosas sustentadas por alguns docentes:

Eu fiquei bolado com o pessoal [coordenadores], porque aqui no colégio eu colocava um funk leve, no interclasse e eles mandavam tirar. Eu peguei e guardei tudo o que eu tinha de funk, porque é muito palha ficar interrompendo a música toda hora. Eu ouvia "tem muita gente dançando, tira essa música", palha isso. Não adianta falar que eles não têm preconceito, porque têm sim, porque eles não curtem, eles só querem saber dessas coisas de rico, de descer para boate, tá doido, isso não é vida real não, tem muito trabalhador que rala muito e curte funk (Aluna 14).

O acontecimento narrado acima sustenta a visão de parte do corpo docente que enxerga o funk como um elemento inadequado à instituição escolar, como mostram os relatos abaiXo:

Então dentro da escola a gente não permite. Mas assim, a gente vai fazer uma mostra cultural, eles podem apresentar um pagode, um hip-hop, pode ser uma valsa, um samba, mas o funk não (professora Suzi).

A menina vai cantar um funk que afirma a ideia que a mulher é um objeto, uma música que acaba estimulando o aluno a reproduzir essas coisas que são negativas, o que pode acabar estimulando o aluno a ter uma atitude mais sexualizada ainda. $\mathrm{Ou}-$ tro ponto também é, então vamos discutir o funk e o que essas letras cheias de sexualidade e apologias a drogas representam, vamos dizer que o funk pode ser outra coisa, mas acho que dessa forma não vamos ter a adesão dos alunos. Eu vejo como um trabalho importante, mas difícil (professora Eduarda).

O posicionamento desses sujeitos leva ao entendimento de que o funk é visto, por uma parcela do corpo docente da instituição, como uma cultura inapropriada ou até mesmo indesejada dentro da escola. Embora exista uma política de negação, sem um prévio debate com os alunos, é importante salientar que, no ano de 2009, o governo do Estado do Espírito Santo elaborou o chamado Currículo Básico das Escolas Estaduais. Esse documento mostra, nos seus princípios norteadores, um conjunto de ações que devem ser realizadas nas unidades de ensino: "Superar as diversas formas de exclusão, de dominação e discriminação é oportunizar que a diversidade seja vivida, experienciada por e com todos os sujeitos" (ESPIRÍTO SANTO, 2009, p. 23).

O interesse dos alunos por esse ritmo tão presente em suas vidas pode se apresentar como uma ponte pedagógica com os demais elementos pertencentes à cultura negra, que, assim como o funk, carecem de um maior destaque no interior do processo educacional. Lopes (2011, p. 18) afirma que o funk é uma mescla de vários ritmos de origem afro, já que possui 
“[...] a fala cantada dos rappers, muitas vezes carrega a energia dos puxadores de escola de samba, a vulnerabilidade do corpo do break é acentuada com o rebolado e a sensualidade do samba, e o sampler vira batida de um tambor ou atabaque eletrônico".

Dentro dessa perspectiva, é importante destacar a lei $\mathrm{n}^{\circ} 10.639 / 03$ e 11.645/082, de 2003, que determina a obrigatoriedade do ensino do estudo da História e Cultura Afrobrasileira e Indígena nas escolas de educação básica de todo o país. Além de criar a possibilidade de se realizar um trato pedagógico com o funk, a implementação dessas leis viabiliza, ainda, que a escola trabalhe didaticamente também com outros elementos vinculados às origens afro-brasileiras, como o jongo, o samba e a capoeira, que por anos estiveram às margens do processo educacional. Seguindo justamente a lógica do trabalho com a cultura negra de modo geral, o funk pode se apresentar como objeto de ensino, já que o ritmo tem origens no movimento afro-americano que sofreu adaptações culturais na cidade do Rio de Janeiro.

Seguindo essa linha de raciocínio, Nascimento e Fonseca (1997) notaram que os alunos de uma determinada escola da zona norte carioca transportavam para o ambiente escolar diversas práticas violentas vivenciadas por eles nos bailes funks da localidade onde moravam. Para tentar superar essa questão, os docentes desenvolveram um trabalho com o ritmo, no intuito de resgatar a visão desse estilo musical enquanto manifestação socialmente produzida em meio à cultura urbana do Rio de Janeiro. O impacto desse trabalho foi sentido pelos pesquisadores ainda durante o processo de intervenção, pois foi observado que alunos participantes assumiam, a cada encontro, outra postura perante o ritmo, tanto no que se refere à capacidade crítica, quanto aos comportamentos já estereotipados do funkeiro frente à sociedade.

Partindo de um posto de vista diferente, Pinelli e Lara (2007) utilizaram a composição de músicas, criação de coreografias e festas com o intuito de levar os alunos e professores a refletirem sobre o funk enquanto uma manifestação ligada diretamente à sexualização exacerbada e aos modismos ligados à lógica de mercado que busca atender aos interesses econômicos. O resultado desse trabalho foi considerado positivo pelas pesquisadoras, já que o estudo colaborou para o enriquecimento do processo de informação e obtenção de uma expressividade corporal consciente a respeito do movimento funk, tanto por parte dos alunos, quanto dos professores. Embora os trabalhos aqui citados tenham adotado diferentes maneiras de pensar e trabalhar o movimento funk, ambos exemplificam a importância de um debate em torno do ritmo no ambiente escolar. Tanto o trabalho de Nascimento e Fonseca (1997) quanto o de Pinelli e Lara (2007) usaram a interdisciplinaridade entre a Educação Física, Sociologia e Português, para pensarem presença do funk em seus contextos.

Já que o funk é uma demanda que está presente na cultura escolar, é possível transformar esse estilo musical em objeto de ensino. Sendo assim, o professor de Educação Física que trate pedagogicamente o funk em suas aulas usará esse objeto para refletir e discutir suas ambiguidades e reelaborá-lo com os alunos na dinâmica escolar. É uma oportunidade, por exemplo, para tematizar o funk ostentação ${ }^{2}$ e a sua vinculação com a indústria cultural ${ }^{3}$.

Desse modo, fomentar dentro do ambiente escolar reflexões a partir dos aspectos culturais do funk - tanto relacionados à identidade das comunidades, irreverência e denúncia de mazelas sociais, quanto às questões que associam o ritmo à criminalidade e à sexualidade exacerbada, entre outros pontos polêmicos - pode contribuir para que os alunos transformem a

\footnotetext{
${ }^{2}$ Pautadas em um mundo luxuoso, as composições do funk ostentação apresentam, em suas canções e videoclipes, diversas descrições de anéis, colares, óculos escuros e boné, acessórios que fazem o sonho de consumo dos jovens compositores, mas que não integram suas realidades. Assim, para realizar os clipes de suas canções, os MCs falsificam relógios e joias. "Fazem cópias de cédulas de dinheiro para exibir o montante. Nos clipes, carros e motos de variadas marcas, são [sic], na verdade, empréstimo dos amigos e de lojas" (FREIRE, L., 2012, p. 5).

${ }^{3}$ Entre vários pontos que Adorno (2009) utiliza para falar sobre a indústria cultural, o autor cita a alienação e a docilidade, causada pelo desejo de consumir. Assim, "[...] para os consumidores não existe mais nada que seja caro. Estes, entretanto, intuem que quanto mais se lhes regala certa coisa, tanto menor se torna o seu preço" (ADORNO, 2009, p. 38).
} 
sua postura perante a sua identificação com esse elemento cultural. Dessa forma, podemos afirmar que o funk pode, sim, ser um objeto de ensino e aprendizagem dentro da Educação Física. Tal como Maciel (2011), que segue a lógica freireana, é necessário dialogar com os conhecimentos que integram as camadas populares, com o intuito de fomentar sua conscientização. Na perspectiva de levar os alunos a refletir sobre a sua apropriação com o funk, foram notadas intervenções esporádicas realizadas por docentes ao observarem ações vinculadas ao ritmo durante as aulas, como aparece no trecho de entrevista abaixo:

Muitas vezes eu vejo eles cantando o funk ostentação. Eu falo para os alunos que eles são de um bairro periférico e questiono de onde vêm os artistas que cantam o funk: eles vêm da periferia ou dos bairros nobres? Como eles sabem que a maioria vem de bairros de periferia, eu questiono: mas, se eles são de bairro de periferia, por que eles cantam que vocês precisam ter o relógio de tal marca, que vocês têm que beber a bebida tal, andar com a moto tal? Mas aí é fazer com que eles reflitam (professor Helder).

O posicionamento desses sujeitos leva ao entendimento de que o funk é visto, por uma parcela do corpo docente da instituição, como uma cultura inapropriada ou até mesmo indesejada dentro da escola. Embora exista uma política de negação, sem um prévio debate com os alunos, é importante salientar que, no ano de 2009, o governo do Estado do Espírito Santo elaborou o chamado Currículo Básico das Escolas Estaduais. Esse documento mostra, nos seus princípios norteadores, um conjunto de ações que devem ser realizadas nas unidades de ensino: "Superar as diversas formas de exclusão, de dominação e discriminação é oportunizar que a diversidade seja vivida, experienciada por e com todos os sujeitos" (ESPIRÍTO SANTO, 2009, p. 23).

De acordo com os dados cedidos pela instituição investigada, é possível notar que o Projeto Político Pedagógico (PPP) da escola ressalta o respeito à diversidade étnica, cultural e socioeconômica, sem preconceito de origem, raça, cor, sexo, credo, idade e quaisquer outras formas de discriminação, tornando possível um trabalho com o ritmo. Entretanto, ao confrontar as ideias propostas pelo PPP da unidade escolar investigada com os dados coletados nas entrevistas, é possível afirmar a existência de algumas lacunas nesse documento, pois assim como a professora Bianca narra:

A proposta pedagógica da escola não fala sobre a violência, não fala sobre o contexto de risco social do bairro. É apenas uma escola que segue o modelo padrão determinado pelo Estado, que não se adapta à realidade (professora Bianca).

A visão da docente encaixa-se dentro da perspectiva de Valle e Salles (2010), que indicam que, muitas vezes, o estilo adotado pelos alunos, principalmente no que diz respeito à música, parece ter significado como produtor de procedimentos incompatíveis com a disciplina desejada na classe, sobretudo no que diz respeito à corporeidade. No entanto, os dados apontam para a necessidade da escola em ter uma visão mais ampliada em relação ao que está acontecendo em seu entorno, rompendo com as barreiras existentes entre os saberes educacionais e a realidade social da região em que a escola está inserida. Carrano (2005) afirma que o principal desafio das unidades de ensino público estaria em derrubar os muros simbólicos construídos ao longo da história e que, em última instância, são os principais responsáveis pela falta de comunicação entre alunos e professores. Dessa forma, situar-se na periferia requer da escola um esforço no sentido de debater e não silenciar o contexto sociocultural levado pelos alunos para dentro da instituição. 


\section{Considerações finais:}

As informações apresentadas ao longo deste artigo mostram que tanto os alunos quanto a maior parcela dos docentes enxergam a importância da visibilidade pedagógica do funk dentro da instituição investigada. Entretanto, a inserção desse elemento cultural entre os saberes educacionais permanece invisível, devido à visão de educadores que enxergam o ritmo como algo inapropriado a esse espaço. Porém, as questões polêmicas que cercam o funk não podem servir de justificativas para a invisibilidade pedagógica do ritmo, uma vez que, como demonstram Pinelli e Lara (2007), as questões relacionadas à sexualidade acerbada e criminalidade podem ser tratadas como maneiras de se discutir junto com os alunos a apropriação desses temas pelo ritmo.

É relevante destacar ainda que os entraves e as aberturas postas pela realidade investigada não representam um caso isolado, mas se somam aos demais encontrados no início desta pesquisa. Dessa forma, ao chamar atenção para a visibilidade do funk, dentro do espaço educacional, este estudo coloca-se na mesma mão dos trabalhos de Nascimento e Fonseca (1997) e Pinelli e Lara (2007) no que se refere à importância de tratar pedagogicamente esse elemento cultural que permeia o cotidiano de muitas instituições espalhadas pelo país.

Destacamos ainda que um diálogo aberto com funk é reconhecer também as suas heranças dentro da cultura brasileira. Assim como indica Facina (2009), em seu processo de nacionalização, o ritmo incorporou técnicas corporais típicas da diáspora africana, tais como o jongo, o samba e a capoeira. Desse modo, reconhecemos a necessidade de construir um debate amplo em torno do funk dentro da escola, reconhecendo-o como um elemento cultural contemporâneo que possui viés complexo, multifacetado e paradoxal, tal como aponta Laignier (2012). Finalizamos este artigo chamando os profissionais da educação a realizarem uma reflexão diante do funk, enquanto um ritmo presente na vida de seus alunos. Entretanto, esse exercício precisa ir além de conversas informais ou de intervenções esporádicas, uma vez que esse diálogo pode contribuir para um maior envolvimento dos estudantes no processo educacional ou, até mesmo, apresentar-se como um elo para intermediar possíveis conflitos que possam existir entre docentes e discentes de uma determinada realidade escolar.

\section{Referências}

ADORNO, T. W. Indústria cultural e sociedade. São Paulo: Paz e Terra, 2009.

BARDIN, L. Análise de conteúdo. Lisboa: Edições 70 Ltda, 1977.

BUOGO, E. C. B; LARA, L. M. A Educação Física nas Diretrizes Curriculares da Educação Básica do Paraná: análise da dança como conteúdo estruturante. Curitiba: SEED/PR, 2009.

CARRANO, P. C. R. Identidades juvenis e escola. Coletiva: Construção coletiva: contribuições à educação de jovens e adultos.- Brasília :UNESCO, MEC, RAAAB, 2005.362p.

CASTELLANI FILHO, L. et al. Metodologia do ensino da educação física. 2. ed. rev. São Paulo: Cortez, 2009.

ESPIRITO SANTO (Estado). Secretaria de Educação. Currículo Básico Escola Estadual. Vitória: SEDU, 2009.

ESSINGER, S. Batidão: uma história do funk. Rio de Janeiro, Record, 2005. 
FACINA, Adriana. "Não Me Bate Doutor": Funk E Criminalização Da Pobreza. V Encontro de Estudos Multidiciplinares em Cultura. Faculdade de Comunicação, Salvador, Bahia, 2009. Disponível em: $<$ http://www.cult.ufba.br/enecult2009/19190.pdf $>$ Acesso em: 18 jun. 2013.

FREIRE, L. S. (2012). Nem luxo, nem lixo: um olhar sobre o funk da ostentação. IX POSCOM, Rio de Janeiro. Disponível em: <http://pucposcom-rj.com.br/wpcontent/uploads/2012/12/4-Libny-Silva-Feire.pdf>. Acesso em: 8 abr. 2015.

FREIRE, P. Pedagogia da autonomia. Saberes necessários à prática educativa. Rio de Janeiro: Paz e Terra, 1997.

GARBIN, E. M; SEVERO, R. C. B. S. Juventudes plurais na escola (des)ordenando tempos e espaços na contemporaneidade. EccoS - Rev. Cient., São Paulo, n. 31, p. 67-82, maio/ago. 2013. Disponível em: https://www.lume.ufrgs.br/bitstream/handle/10183/127977/000973219.pdf?sequence=1. Acesso em: 6 abr. 2015.

LAIGNIER, P. C. Pedagogias do funk carioca: Deus e o Diabo na terra do som. MATRIZes, São Paulo, v. 6, n. 1-2, p. 207-230, 2012. Disponível em: <http://www.redalyc.org/comocitar.oa?id=143024819014>. Acesso em: 30 abr. 2018.

LOPES, A. C. Funke-se quem quiser: no batidão negro da cidade carioca. Rio de Janeiro: Bom Texto, 2011.

MACIEL, K. D. F. O pensamento de Paulo Freire na trajetória da educação popular. Educação em Perspectiva, Viçosa, 2011. Disponível em: <https://doi.org/10.22294/eduper/ppge/ufv.v2i2.196>. Acesso em: 28 abr. 2018.

MEDEIROS, J. Funk carioca: crime ou cultura? O som dá medo. E prazer. São Paulo: Terceiro Nome, 2006.

MINAYO, C. (Org.). Pesquisa Social: Teoria, método e criatividade. 31. ed. Petrópolis, RJ: Vozes, 2012.

NASCIMENTO. M. A; FONSECA, M. A. O funk e as aulas de Educação Física: uma proposta de resgate cultural em uma escola pública do Rio de Janeiro. Lecturas: Educación Física e Deportes, Buenos Aires, n. 8, p. 1-2, dez. 1997. Disponível em: <http://www.efdeportes.com/efd8/funk8.htm>. Acesso em: 22 set. 2013.

PINELLI, T. M. L; LARA, L. M. Trá-lá-lá... que dança é essa? funk na escola: um olhar crítico sobre a linguagem corporal. Instituição: UEL, 2007. Disponível em: <http://www.gestaoescolar.diaadia.pr.gov.br/arquivos/File/producoes_pde/artigo_tania_maria _lopes_pinelli.pdf>. Acesso em: 20 set. 2013.

RANGEL, P. L. N. O funk no Rio de Janeiro: identidade étnica, cultural e social na baixada fluminense. Revista Periferia, v. 5, n. 2, p. 113-130, 2013. Disponível em: <http://epublicacoes.uerj.br/index.php/periferia/article/view/15370>. 
ROSÁRIO, J. A estética do tamborzão - A trajetória do Funk Carioca (2015). Disponível em: <http://issuu.com/jotarosario/docs/artigo_-_a_est_tica_do_tamborz_o>. Acesso em: 01 maio 2015.

SILVA, E.M. et al. A Escola e a cultura do jovem de periferia 2004. Disponível em: <http://alb.com.br/arquivo-morto/edicoes_anteriores/anais15/alfabetica/StoriNorberto.htm >. Acesso em: 20. jul.2013.

SILVA, F. C. T. Cultura escolar: quadro conceitual e possibilidades de pesquisa. Educar em revista, Curitiba, v. 22, n. 28, p. 201-216, jul./dez. 2006.

SOUZA, R. M. Escola e Juventude: o aprender a aprender. São Paulo: EDUC, 2003.

VALE, F. F. do; SALLES, L. M. F. Jovens de periferia, estilos musicais e cotidiano escolar. EccoS, São Paulo, v. 12, n. 2, p. 365-384, jul./dez. 2010.

VIANNA, H. O mundo do funk carioca. Rio de Janeiro: Jorge Zahar, 1988.

Recebido em: $16 / 05 / 2017$

Revisado em: 23/04/2018

Aprovado em: 25/06/2018

Endereço para correspondência:

fqalmeida@hotmail.com

Felipe Quintão Almeida

Universidade Federal do Espírito-Santo

Av. Fernando Ferrari, 514, Goiabeiras

Vitória - ES - CEP 29075-910 